\title{
ПОСЕЛЕНИЯ, НАЗВАННЫЕ ГОРОДАМИ, В «ЦЕРКОВНОЙ ИСТОРИИ» ФЕОДОРИТА КИРСКОГО
}

\section{THE SETTLEMENTS CALLED THE CITIES IN «CHURCH HISTORY» BY THEODORET OF CYRUS}

\author{
Д.А. Гоголев \\ D.A. Gogolev \\ Тюменский государственный университет, \\ Россия, 625003, г. Тюмень, ул. Володарского, 6 \\ University of Tyumen, 6 Volodarskogo St, Tyumen, 625003, Russia \\ E-mail: dmalgogolev@gmail.com
}

\begin{abstract}
Аннотация
Целью статьи является выявление характера использования термина полис в «Церковной истории» Феодорита Кирского. Методы исследования: общенаучные методы анализа, синтеза и историзма, исторический нарратив, историко-генетический и историко-типологический методы, сравнительный анализ источников и историографии, критика исторического источника. Результаты исследования: 1) круг поселений, обозначаемый термином полис, достаточно широк и составляет около трети от общего числа поселений, упомянутых в «Церковной истории»; географически это преимущественно восточные провинции; 2) все населенные пункты, называемые полисами, могут быть разделены на несколько групп в зависимости от характера упоминания: крупнейшие церковные или административные центры; поселения, связанные с присутствием там христианских деятелей; поселения, связанные с церковной жизнью; 3) населенные пункты, называемые термином полис, были в основном крупными или значительными городскими центрами; в источниках, близких по времени, они далеко не всегда обозначаются как полис.
\end{abstract}

\begin{abstract}
The purpose of the article is to identify the nature of the use of the term polis in «Church history» of the Theodoret of Cyrus. Research methods: general scientific methods of analysis, synthesis and historicism, historical narrative, historical-genetic and historical-typological methods, comparative analysis of sources and historiography, criticism of a historical source. The results of the study: 1) the circle of settlements indicated by the term polis is wide enough and makes up about one third of the total number of settlements mentioned in the «Church history»; geographically these are mainly eastern provinces; 2) all populated areas, called polis, can be divided into several groups according to the nature of the mention: the largest church or administrative centers; settlements related to the presence of Christian figures there; settlements related to church life; 3 ) settlements, called the term polis, were mainly large or significant urban centers; in sources close in time, they are far from always designated as polis.
\end{abstract}

Ключевые слова: Римская империя, поздняя античность, Феодорит Кирский, города, терминология, полис.

Keywords: Roman Empire, late antiquity, Theodoret of Cyrus, cities, terminology, polis.

Изучение терминологии городских поселений не часто становится предметом исследования применительно к текстам позднеантичных «Церковных историй». Нередко исследователи абсолютизируют те понятия, которые применяли современники описываемых в источниках событий. В частности, предлагается называть городами те пункты, которые в эпоху 
поздней античности или средневековья обозначались урбанистическими терминами. Историк «обязан выяснить, каковы те хозяйственные, социальные и политические особенности, благодаря которым отдельные населенные пункты назывались «городами» [Сюзюмов, 1967, с. 39].

В статье будет предпринята попытка определить, все ли названные городами населенные пункты в «Церковной истории» Феодорита являлись таковыми.

Объектом исследования является текст «Церковной истории» Феодорита Кирского, одного из важнейших сочинений в своем жанре, а предметом - упоминания конкретных поселений, обозначаемых автором в качестве полисов.

К «Церковной истории» обращались многие исследователи позднеантичной церковной исторической мысли [Кривушин, 1998, с. 175-197; Leppin, 2003; Pásztori-Kupán, 2006; Schor, 2011]. В меньшей степени на этот труд ссылаются авторы историкоурбанистических штудий. По мнению И.Ю. Ващевой, для Феодорита, как и для ряда других позднеантичных писателей, географические детали, точное местоположение тех или иных объектов не имели большого значения [Ващева, 2013, с. 443]. Особенности использования городской терминологии в позднеантичных и ранневизантийских источниках исследовались и по отношению к римским историкам III-IV вв. [Козлов, 1992; Лебедев, 2010], и грекоязычным авторам VI - 1-й пол. VII вв. [Saradi, 2006].

Цель статьи - выявить, какие поселения именуются в «Церковной истории» термином полис. При этом не будут анализироваться многочисленные случаи обозначения населенных пунктов в качестве полисов без упоминаний топонимов.

Следует отметить, что некоторые населенные пункты обозначаются в тексте «Церковной истории» различными терминами. Так, Антиохия, Александрия, Константинополь и Самосата - одновременно и полисы, и асти, Кукуз - полис и полихнион [Гоголев, 2017, c. 281-284]. В латиноязычных источниках поздней античности и раннего средневековья также имеется немало подобных примеров, когда «даже в рамках небольшого текста населенный пункт обозначается разными терминами» [Филиппов, 2000, с. 235].

Всего в «Церковной истории» упоминается 62 поселения, которые могут быть причислены к городам, 28 из них обозначены термином полис. Также автор использует термин асти. Все упоминания можно разделить на категории по объему и тематике.

Самые краткие упоминания - те, которые присутствуют в названии мест служения того или иного церковного иерарха, преимущественно епископа.

Наибольшее количество упоминаний у следующих городов: Александрия, Антиохия, Константинополь, Медиолан, Никея, Рим, как с добавлением нарицательного обозначения полис, так и без него. Всех их (за исключением Медиолана) объединяет то, что они являлись крупными церковными центрами.

Термином полис названы поселения в следующих случаях:

1. Как места ссылки или гонений против христиан.

Группа населенных пунктов в «Церковной истории» Феодорита связана с деятельностью ссыльных, изгнанных, подвергнутых гонениям христиан. В историографии детально изучены места ссылки и деятельность осужденных [Stevenson, 2014]. В «Церковной истории» дано множество примеров «о мужественном и даже дерзком поведении перед лицом еретиков и язычников ортодоксальных пастырей, подвижников и других защитников истины» [Кривушин, 1998, с. 186].

Египетский город Антиной (Антиноэ, Антинополь) был основан императором Адрианом в честь своего фаворита Антиноя, при Диоклетиане становится столицей Фиваиды. В источниках IV-VI вв. неоднократно известен как место, куда направлялись неугодные властям светские или церковные деятели. По приказу императора Валента в Антинополь были сосланы эдесские пресвитеры Евлогий и Протоген. «Когда в том городе ( номышленного себе епископа и стали участвовать в церковных собраниях, то увидели, что собиравшихся было очень немного, и, расспрашивая о причине, узнали, что почти все жители того города (лó $\lambda \iota v)$ эллины» [Theod. HE IV.18]. После того, как император Феодосий возвратил их из изгнания, Евлогий стал епископом в Эдессе, а Протоген позднее был рукоположен в 
епископы города Карры. Антинополь и в VI в. оставался местом заточения неугодных: префект Востока в 532-541 гг. Иоанн Каппадокийский ненадолго находился там в ссылке, а после смерти императрицы Феодоры в 548 г. возвратился в Константинополь. Иной аспект в изображении Антинополя содержится в «Лавсаике» Палладия Еленопольского (360-420 гг.). Его более интересовала монашеская жизнь, когда он писал, что четыре года прожил «в фиваидском городе Антиное и в это время узнал обо всех тамошних монастырях».

Диокесарией в правление императора Адриана (117-138 гг.) стал называться город Cепфорис. B IV в. он находился на территории образованной в ходе административных реформ императора Диоклетиана провинции Палестина II, в центре Галилеи. В окружении иудейского населения в городе существовала в меньшинстве христианская община во главе с епископом. Сюда в 373 г., «в обитаемый господоубийцами иудеями город Диокесарию ( 11 египетских епископов за исповедание никейской веры. Полисом называет Диокесарию и Сократ Схоластик: Констанций Галл повелел разрушить ее до основания, чтобы отомстить жителям Диокесарии, делавшим набеги на римскую территорию [Socrat. II.33]; в этой же связи пишет о Диокесарии Созомен, но без обозначения ее полисом.

Гелиополь (Илиополь) в Финикии являлся оплотом язычества и «сделался столь знаменитым своей враждой к христианству, что христиане были изгоняемы туда из Александрии в качестве особого наказания» [Лопухин, 1904, кол. 859]. Местная знать исповедовала язычество до второй половины VI в. [Ведешкин, 2015, с. 220].

Карры оставались значительным языческим культовым центром Сирии [Ведешкин, 2015 , с. 219]. Протоген, как уже отмечалось, был рукоположен в епископы и «получил пове-

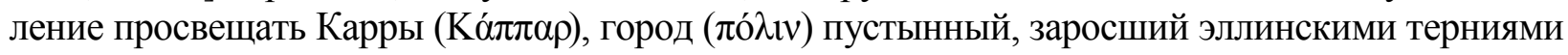
и требовавший неутомимого трудолюбия» [Theod. IV.18]. Евлогий в лице Протогена, по словам Феодорита, «подарил врача-целителя болезновавшему тогда городу (ло́́єı) Каррам» [Theod. V.4]. Феодорит описывает случай издевательства Юлиана над его жительницей, так что «город (ло́ $\imath \rho)$ Карры доселе сохраняет памятники этого нечестия» [Theod. 3.26]. Созомен дает схожую информацию, но не употребляет термин полис. Интересно, что Аммиан Марцеллин применяет термин oppidum, когда во время своего похода на восток «в древний город Карры (Carras antiquum oppidum)» прибыл император Юлиан [Amm. Marc. XXIII.3.1].

Оксиринх. Аммиан Марцеллин причисляет его к величайшим городам (maximis urbibus). По приказу императора Валента II, сторонника арианства, началось гонение на противников этого учения. Церковные деятели (Мелетий Антиохийский, Евсевий Самосатский и др.) не по своей воле оказались на территории различных провинций [Гидулянов, 1908, с. 335]. В их числе оказался и епископ Эдессы Варса, который был сослан в

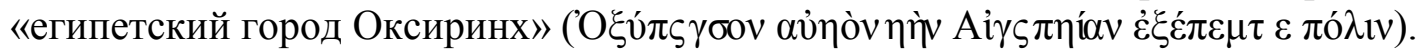

Тривера (Августа Треверов, Трир). Здесь в изгнании находился Афанасий Великий, архиепископ Александрии. В результате необоснованных обвинений он был осужден Тирским собором и низложен. Феодорит сообщает: император «сослал Афанасия в один

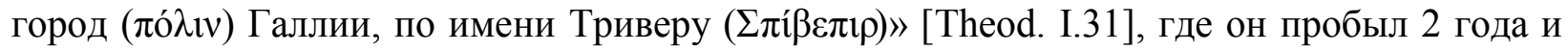
4 месяца, после чего возвратился в Александрию. Сократ Схоластик и Созомен также упоминают о Тривере как месте ссылки Афанасия, но не называют его полис. Только Зосим в «Новой истории» использует для обозначения Триверы термин полис [Zosim. III.7].

Газа, значительный культурный и экономический центр Восточного Средиземноморья (Южная Палестина), лишь к концу V в. освобождается от язычества, хотя появление христианства в этом регионе относится к I в. н. э. [Ведешкин, 2015, с. 210-217]. Совсем рядом находился еще один важный город Аскалон. Феодорит сообщает, что в палестинских городах (ло́́えєı) Аскалоне и Газе много мучеников пострадали от рук гонителей христианской веры [Theod. III.7]. Созомен несколько раз по другому поводу употребляет термин полис при упоминании Газы, а в анонимном географическом трактате «Полное описание Вселенной и народов» Аскалон и Газа - «весьма выдающиеся города (civitates) c оживленной торговлей, изобилующие всем» [Анонимный..., 1956, с. 280]. 
Доростол обозначен в «Церковной истории» как «знатный фракийский город» (ло́ $1 р$

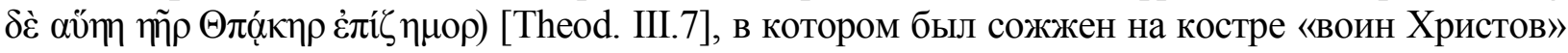
Эмилиан. Его мученическая кончина - случай, когда убиенным выступает раб местного градоначальника, а не служитель церкви [Пак, 2012, с. 126]. Позднее Доростол перечисляется среди укреплений (ỏøs

2. Как места, связанные с иерковной жизнью.

Афины обозначены как полис в то время, когда в город прибыл апостол Павел [Theod. V.39]. В эпоху поздней античности Афины обозначены как «ло́ V.5], который выстоял в противостоянии с Аларихом. Евнапий называл Афины городом ( $\pi$ ó $\varepsilon v 0$ ) при описании ситуации социальной напряженности [Eunap. Vita soph. IX.1.6].

Бероя в эпоху поздней античности - один из крупных городов Сирии. Феодорит упоминает епископа Акакия, который «имел свою паству в сирском городе (ло́ $\varepsilon \varepsilon \rho \rho)$ Бероэ» [Theod. V.23]. Следует отметить, что Страбон перечислял Берою среди маленьких

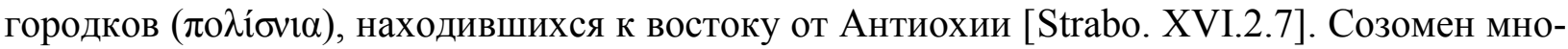
гократно упоминает Берою без термина.

Ника - место, где в 359 г. собрались епископы на так называемый собор [Карташев, 1994, с. 86]. Феодорит отмечает, что часть епископов была переведена во фракийский

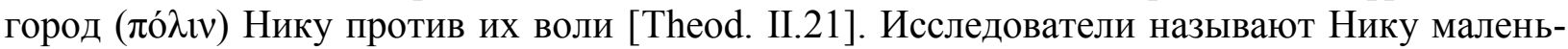
ким местечком под Адрианополем, почтовой станцией [Карташев, 1994, с. 86]. Полис употребляют при описании одних и тех же событий здесь, наряду с Феодоритом, и Созомен «проезжая Фракию, остановились в городе (

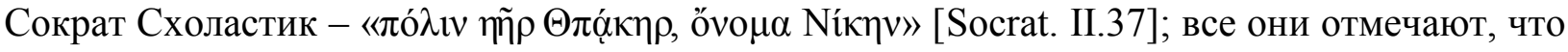
Ника находится во Фракии. Аммиан Марцеллин же называет Нику военным постом (statio), куда прибыл перед сражением при Адрианополе в 378 г. император Валент [Amm. Marc. XXXI.11.2]. Необходимо отметить, что в трактате «О постройках» Прокопия Кеса-

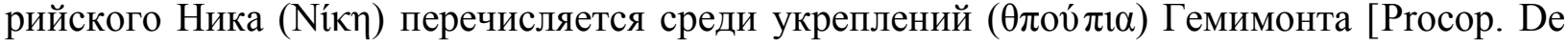
aedif. IV.11.20]. Примечательно, что Феодорит называет Нику городом, несмотря на незначительность этого места. Это можно объяснить, на наш взгляд, тем, что для Феодорита все места, связанные с церковной жизнью, являются городами.

Самосата являлась древним городом в провинции Евфратисия. Феодорит, как уже отмечалось, дважды называет этот населенный пункт асти [Theod. IV.14]. Столько же раз употреблен и термин полис: во-первых, когда самосатский епископ Евсевий «возвратился в вверенный себе город ( $\pi$ ó $\lambda \mathrm{v})$ ) [Theod. II.32], во-вторых, автор отметил «ненависть, которую питал этот город (ло́ $\lambda \rho \rho)$ к последователям Ария» [Theod. IV.15].

Сардика являлась местом проведения собора 342-343 гг. [Карташев, 1994, c. 68-72]. Феодорит писал: «Констанций издал повеление, чтобы как восточные, так и за-

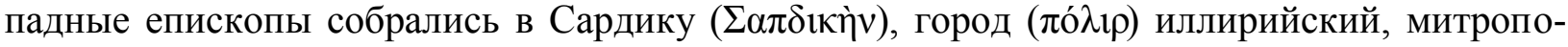
лию дакийской провинции» [Theod. II.4]. Полисом называет Сардику и Сократ Схоластик [Socrat. II.20], а Созомен многократно упоминает город, но без обозначения его как полис.

3. Случаи, когда указывается особое географическое или административное положение поселения.

Селевкия у Феодорита - город (ло́ $\imath \rho)$, «который находится в Исаврии, лежит при море и почитается главным во всей провинции» [Theod. II.26]. Здесь продолжились заседания созванного по инициативе императора Констанция II Аримино-Селевкийского собора в 359 г. [Карташев, 1994, с. 87]. Сократ Схоластик обозначил Селевкию как полис также в связи с событиями 359 г.: «объявлен вселенский Собор в иллирийском городе Сардике» [Socrat. II.20].

Германикия, писал Феодорит, - это «город (ло́ $\imath \iota)$ ), лежащий на границе Каппадокии с Киликией и Сирией, принадлежит к так называемой евфратской епархии» [Theod. II.25]. Сократ Схоластик несколько раз называл Германикию полисом [Socrat. II.37].

Нерония - город ( $\pi$ ó $\lambda \iota \rho)$ второй Киликии, который теперь называется Иринополис [Theod. I.7]. Феодорит упоминает епископа Неронии Наркиса и указывает на то, что город сейчас называется Иринополь. 


\section{Ocada.}

Феодосиополь, ранее именовавшийся Карин, после раздела Великой Армении в 387 г. отошел к Восточной Римской империи и был укреплен императором Феодосием II. Во время войны с Персией войска шаханшаха Бахрама V 30 дней пытались взять его. Феодорит отмечал, что «неприятели, осаждая соименный царю город (ло́ лости Божией, оказались достойными смеха» [Theod. V.37].

5. Упоминание о действиях язычников в городах.

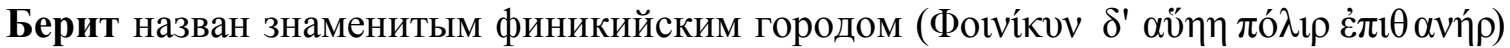
[Theod. IV.22], где во времена Юлиана была сожжена церковь. В более поздних источниках Берит торжественно именуется «civitatem splendidissimam» («Путник Антонина из Плаценции»), «прекрасный Берит, гордость Финикии» [Agath. Myr. II.15].

Эмеса - город в Сирии, на рубеже IV-V вв. стала центром вновь образованной провинции Финикия II. В «городе ( ную церковь и поставили в ней достойный смеха мужеско-женский кумир» [Theod. III.7].

Как следует из вышеизложенного, в «Церковной истории» Феодорита Кирского содержатся упоминания значительного числа поселений, которые также присутствуют в трудах Сократа Схоластика, Созомена и других церковных историков и прочих авторов IV-VI вв. Количество одноименных населенных пунктов, которые названы городами и в «Церковной истории», и у других писателей, невелико.

Городами для Феодорита (в контексте событий церковной истории) являются прежде всего места, связанные с деятельностью ссыльных, осужденных, подвергавшихся гонениям, а также населенные пункты, наполненные событиями церковной жизни.

\section{Список литературы}

1. Аммиан Марцеллин 2005. Римская история. Пер. Ю.А. Кулаковского, А.И. Сонни. М., АСТ, Ладомир, 640.

2. Анонимный географический трактат «Полное описание вселенной и народов». 1956. Пер. С.В. Поляковой и И.В. Феленковской. Византийский временник. 8 (33): 277-305.

3. Ващева И.Ю. 2013. Феномен «Церковных историй» в эпоху поздней античности. Дисс. д. и. н. Нижний Новгород, 789.

4. Ведешкин М.А. 2015. Языческая оппозиция христианизации Римской империи (IV-VI вв.). Дисс. канд. ист. наук. М., 316.

5. Гидулянов П.В. 1908. Восточные патриархи в период четырех первых Вселенских соборов. Ярославль, Типография губернского правления, 774.

6. Гоголев Д.А. 2017. Особенности урбанистической терминологии в «Церковной истории» Феодорита Кирского. Древний мир: история и археология. Труды международной научной конференции «Дьяковские чтения» (Москва, 3 декабря 2016 г.). М., МПГУ, 279-286.

7. Кареев Д.В. 2018. Сражения у крепости Сингара и римско-персидские войны Констанция II: к вопросу о хронологии и последовательности событий. Проблемы истории, филологии, культуры. 4: 135-152.

8. Карташев А.В. 1994. Вселенские соборы. М., Республика, 542.

9. Козлов А.С. 1992. Комит Марцеллин о позднеантичном городе. Античная древность и средние века. 26: 46-55.

10. Кривушин И.В. 1998. Ранневизантийская церковная историография. СПб., Алетейя, 300.

11. Лебедев П.Н. 2010. Провинциальные города в представлениях римских историков III-IV вв. н. э. Город в Античности и Средневековье: общеевропейский контекст. Доклады международной научной конференции. Под ред. В.В. Дементьевой. Ч. 1. Ярославль, ЯрГУ, 94-97.

12. Пак Е.А. 2012. Традиция о мучениках времен императора Юлиана Отступника. Вестник Санкт-Петербургского университета. Сер. 2. История. 2: 122-129.

13. Сократ Схоластик. 1996. Церковная история. Пер. под. ред. И.В. Кривушина. М., РОССПЭН, 368.

14. Сюзюмов М.Я. 1967. Византийский город (середина VII - середина IX в.). Византийский временник. 27: 32-70. 
15. Феодорит Кирский. 1993. Церковная история. М., Российская политическая энциклопедия; Православное товарищество «Колокол», 239.

16. Филиппов И.С. 2000. Средиземноморская Франция в раннее средневековье. Проблема становления феодализма. М., Скрипторий, 2000, 800.

17. Церковная история Эрмия Созомена Саламинского. 1851. СПб., В типографии Фишеpa, 636+XXXIV.

18. Ammianus Marcellinus 1970. Römische Geschichte. Lateinisch und Deutsch und mit einem Kommentar versehen von W. Seyfarth. Band 3: Buch 22-25. Berlin, Akademie-Verlag, 255.

19. Ammianus Marcellinus 1978. Römische Geschichte. Lateinisch und Deutsch und mit einem Kommentar versehen von W. Seyfarth. Band 4: Buch 26-31. Berlin, Akademie-Verlag, 1978, 401.

20. Lenski N. 2004. Valens and the Monks: Cudgeling and Conscription as a Means of Social Control. Dumbarton Oaks Papers. 58: 93-117.

21. Leppin H. 2003. The Church Historians: Socrates, Sozomenus, and Theodoretus. Greek and Roman Historiography in Late Antiquity: fourth to sixth century A.D. Ed. by G. Marasco. Leiden, 219-254.

22. Pásztori-Kupán I. 2006. Theodoret of Cyrus. London - New York, Routledge, 296.

23. Procopius Caesariensis 2001. De aedificiis libri VI. Opera omnia. Rec. J. Haury, ed. G. Wirth. Vol. IV. München, Leipzig, K.G. Saur Verlag, XII+408.

24. Saradi H. 2006. The Byzantine City in the Sixth Century: Literary Images and Historical Reality. Athens, Perpinia, 543.

25. Schor A.M. 2011. Theodoret's People: Social Networks and Religious Conflict in Late Roman Syria. Berkeley - Los Angeles - London, University of California Press, XV+342.

26. Socrates 1878. Ecclesiastical History. Ed. R. Hussey. Oxford, Clarendon Press, XXVIII+343.

27. Sozomenus 1960. Kirchengeschichte. Hrsg. von J. Bidez. G.C. Hansen. Berlin, AkademieVerlag, LXVII+525. $68,7-27$

28. Stevenson W. 2014. Exiling Bishops: The Policy of Constantius II. Dumbarton Oaks Papers.

29. Theodoret 1954. Kirchengeschichte. Hrsg. von L. Parmentier, bearb. von F. Scheidweiler. Berlin, Akademie-Verlag, XXIX+445.

30. Zosimus 1837. Historia nova. Ed. I. Bekker. Bonn, Impensis E. Weberi, 255.

\section{References}

1. Ammian Marcellin 2005. Rimskaja istorija [Roman history]. Per. Ju.A. Kulakovskogo, A.I. Sonni. Moscow, AST, Ladomir, 640.

2. Anonimnyj geograficheskij traktat «Polnoe opisanie vselennoj i narodov» [Anonymous geographical treatise «A Complete Description of the Universe and Peoples»]. 1956. Per. S.V. Poljakovoj i I.V. Felenkovskoj. Vizantijskij vremennik [Byzantine temporary]. 8 (33): 277-305.

3. Vashheva I.Ju. 2013. Fenomen «Cerkovnyh istorij» v jepohu pozdnej antichnosti [The Phenomenon of the «Church Histories» in Late Antiquity]. Diss. d. i. n. Nizhniy Novgorod, 789.

4. Vedeshkin M.A. 2015. Yazycheskaya oppozitsiya khristianizatsii Rimskoy imperii (IV-VI vv.) [Pagan Opposition to Christianization of the Roman Empire (IV-VI centuries A. D.)]. Diss. k. i. n, Moscow, 316 .

5. Gidulyanov P.V. 1908. Vostochnye patriarkhi v period chetyrekh pervykh Vselenskikh soborov [Eastern patriarchs during the first four Ecumenical Councils]. Yaroslavl', Tipografiya gubernskogo pravleniya, 774.

6. Gogolev D.A. 2017. Osobennosti urbanisticheskoj terminologii v «Cerkovnoj istorii» Feodorita Kirskogo [Features of Urban Terminology in "Church History» of Theodoret of Cyrus]. Drevnij mir: istorija i arheologija. Trudy mezhdunarodnoy nauchnoy konferentsii «D'jakovskie chtenija» (Moskva, 3 dekabrja 2016 g.). [Ancient World: History and Archeology. Works of the International Scientific Conference «Dyakov Readings» (Moscow, 3 December, 2016)]. Moscow, MPGU, 279-286.

7. Kareev D.V. 2018. Srazhenija u kreposti Singara i rimsko-persidskie vojny Konstancija II: k voprosu o hronologii i posledovatel'nosti sobytij [Battle of the fortress Singara and Roman-Persian wars of Constantius II: the chronology and sequence of events]. Problemy istorii, filologii, kul'tury [Problems of history, philology, culture]. 4: 135-152.

8. Kartashev A.V. 1994. Vselenskie sobory [Ecumenical council]. Moscow, Respublika, 542. 
9. Kozlov A.S. 1992. Komit Marcellin o pozdneantichnom gorode [Marcellinus Comes about City in Late Antiquity]. Antichnaja drevnost' i srednie veka. 26: 46-55.

10. Krivushin I.V. 1998. Rannevizantijskaja cerkovnaja istoriografija [Early Byzantine Church Historiography]. Saint Petersburg, Aletheia, 300.

11. Lebedev P.N. 2010. Provincial'nye goroda v predstavlenijah rimskih istorikov III-IV vv. n. je. [Representation of provincial cities in the works of roman historians in the 3rd and 4th centuries A. D.]. Gorod v Antichnosti i Srednevekov'e: obshheevropejskij kontekst. Doklady mezhdunarodnoy nauchnoy konferentsii. Pod red. V.V. Dement'evoj. Ch. 1 [The City in Antiquity and Middle Ages: All-european Context International. Reports of International Scientific Conference. Vol. 1]. Yaroslavl, JarGU: 94-97.

12. Pak E.A. 2012. Traditsiya o muchenikakh vremen imperatora Yuliana Otstupnika [The tradition of martyrs of the time of Julian the Apostate]. Vestnik Sankt-Peterburgskogo universiteta [Bulletin of St. Petersburg University]. Ser. 2. Istoriya. 2: 122-129.

13. Sokrat Skholastik. 1996. Tserkovnaya istoriya [Church history]. Per. pod red. I.V. Krivushina. Moscow, ROSSPEN, 368.

14. Syuzyumov M.Ya. 1967. Vizantiyskiy gorod (seredina VII - seredina IX v.) [Byzantine city (mid-VIIth - mid-IXth century)]. Vizantiyskiy vremennik [Byzantine temporary]. 27: 32-70.

15. Feodorit Kirskiy. 1993. Tserkovnaya istoriya [Church history]. Moscow, Rossiyskaya politicheskaya entsiklopediya; Pravoslavnoe tovarishchestvo «Kolokol», 239.

16. Filippov I.S. 2000. Sredizemnomorskaya Frantsiya v rannee srednevekov'e. Problema stanovleniya feodalizma [Mediterranean France in the early Middle Ages. The problem of the formation of feudalism]. Moscow, Skriptoriy, 800.

17. Tserkovnaya istoriya Ermiya Sozomena Salaminskogo [Church History of Hermia Sozomen Salaminsky]. 1851. Saint Petersburg, V tipografii Fishera, 636+XXXIV.

18. Ammianus Marcellinus 1970. Römische Geschichte. Lateinisch und Deutsch und mit einem Kommentar versehen von W. Seyfarth. Band 3: Buch 22-25. Berlin, Akademie-Verlag, 255.

19. Ammianus Marcellinus 1978. Römische Geschichte. Lateinisch und Deutsch und mit einem Kommentar versehen von W. Seyfarth. Band 4: Buch 26-31. Berlin, Akademie-Verlag, 1978, 401.

20. Lenski N. 2004. Valens and the Monks: Cudgeling and Conscription as a Means of Social Control. Dumbarton Oaks Papers. 58: 93-117.

21. Leppin H. 2003. The Church Historians: Socrates, Sozomenus, and Theodoretus. Greek and Roman Historiography in Late Antiquity: fourth to sixth century A.D. Ed. by G. Marasco. Leiden, 219-254.

22. Pásztori-Kupán I. 2006. Theodoret of Cyrus. London - New York, Routledge, 296.

23. Procopius Caesariensis 2001. De aedificiis libri VI. Opera omnia. Rec. J. Haury, ed. G. Wirth. Vol. IV. München, Leipzig, K.G. Saur Verlag, XII+408.

24. Saradi H. 2006. The Byzantine City in the Sixth Century: Literary Images and Historical Reality. Athens, Perpinia, 543.

25. Schor A.M. 2011. Theodoret's People: Social Networks and Religious Conflict in Late Roman Syria. Berkeley - Los Angeles - London, University of California Press, XV+342.

26. Socrates 1878. Ecclesiastical History. Ed. R. Hussey. Oxford, Clarendon Press, XXVIII+343.

27. Sozomenus 1960. Kirchengeschichte. Hrsg. von J. Bidez. G.C. Hansen. Berlin, AkademieVerlag, LXVII+525.

28. Stevenson W. 2014. Exiling Bishops: The Policy of Constantius II. Dumbarton Oaks Papers. $68,7-27$.

29. Theodoret 1954. Kirchengeschichte. Hrsg. von L. Parmentier, bearb. von F. Scheidweiler. Berlin, Akademie-Verlag, XXIX+445.

30. Zosimus 1837. Historia nova. Ed. I. Bekker. Bonn, Impensis E. Weberi, 255.

\section{Ссылка для цитирования статьи Link for article citation}

Гоголев Д.А. 2020. Поселения, названные городами, в «церковной истории» Феодорита Кирского. Via in tempore. История. Политология, 47(1): 47-53. DOI 10.18413/2687-0967-2020-47-1-47-53

Gogolev D.A. 2020. The settlements called the cities in «church history» by Theodoret of Cyrus. Via in tempore. History and political science, 47(1): 47-53 (in Russian). DOI 10.18413/2687-0967-2020-47-1-47-53 